\title{
Sol-gel dip coating of yttria-stabilized tetragonal zirconia dental ceramic by aluminosilicate nanocomposite as a novel technique to improve the bonding of veneering porcelain
}

\author{
This article was published in the following Dove Press journal: \\ International Journal of Nanomedicine \\ 14 July 2016 \\ Number of times this article has been viewed
}

\author{
Azamsadat Madani' \\ Mohammadreza Nakhaei \\ Parisa Karami ${ }^{3}$ \\ Ghadir Rajabzadeh ${ }^{4}$ \\ Sahar Salehi ${ }^{4,5}$ \\ Hossein Bagheri ${ }^{6}$ \\ 'Dental Research Center, Department \\ of Prosthodontics, Faculty of \\ Dentistry, Mashhad University \\ of Medical Sciences, ${ }^{2}$ Dental Materials \\ Research Center, Department of \\ Prosthodontics, Faculty of Dentistry, \\ Mashhad University of Medical \\ Sciences, Mashhad, ${ }^{3}$ Department \\ of Prosthodontics, Faculty of \\ Dentistry, Zanjan University of \\ Medical Sciences, Zanjan, ${ }^{4}$ Department \\ of Nanotechnology, Research Institute \\ of Food Science and Technology, \\ Mashhad, ${ }^{5}$ Department of Material and \\ Metallurgical Engineering, University \\ of Semnan, Semnan, ${ }^{6}$ Dental Materials \\ Research Center, Department \\ of Operative Dentistry, Mashhad \\ University of Medical Sciences, \\ Mashhad, Iran
}

\begin{abstract}
The aim of this in vitro study was to evaluate the effect of silica and aluminosilicate nanocomposite coating of zirconia-based dental ceramic by a sol-gel dip-coating technique on the bond strength of veneering porcelain to the yttria-stabilized tetragonal zirconia polycrystal (Y-TZP) in vitro. Thirty Y-TZP blocks $(10 \mathrm{~mm} \times 10 \mathrm{~mm} \times 3 \mathrm{~mm})$ were prepared and were assigned to four experimental groups ( $\mathrm{n}=10$ /group): $\mathrm{C}$, without any further surface treatment as the control group; S, sandblasted using $110 \mu \mathrm{m}$ alumina powder; $\mathrm{Si}$, silica sol dip coating + calcination; and $\mathrm{Si} / \mathrm{Al}$, aluminosilicate sol dip coating + calcination. After preparing Y-TZP samples, a $3 \mathrm{~mm}$ thick layer of the recommended porcelain was fired on the coated Y-TZP surface. Fourier transform infrared spectroscopy (FT-IR), X-ray diffraction (XRD), scanning electron microscopy (SEM), and energy-dispersive X-ray analysis were used to characterize the coating and the nature of the bonding between the coating and zirconia. To examine the zirconia-porcelain bond strength, a microtensile bond strength ( $\mu \mathrm{TBS}$ ) approach was chosen. FT-IR study showed the formation of silica and aluminosilicate materials. XRD pattern showed the formation of new phases consisting of $\mathrm{Si}, \mathrm{Al}$, and $\mathrm{Zr}$ in coated samples. SEM showed the formation of a uniform coating on Y-TZP samples. Maximum $\mu$ TBS values were obtained in aluminosilicate samples, which were significantly increased compared to control and sandblasted groups ( $P=0.013$ and $P<0.001$, respectively). This study showed that aluminosilicate sol-gel dip coating can be considered as a convenient, less expensive reliable method for improving the bond strength between dental Y-TZP ceramics and veneering porcelain.
\end{abstract}

Keywords: dip coating, zirconia, porcelain, bond strength

\section{Introduction}

Development of high-strength dental ceramics such as yttria-stabilized tetragonal zirconia polycrystal (Y-TZP) has made it possible to fabricate all-ceramic restorations with superior aesthetic properties. The strengthening mechanism known as "transformation toughening" has made it possible to use Y-TZP as crown and bridge frameworks instead of metals. Moving from "ceramic fused to metal" toward "all-ceramic" restorations, the techniques for fabricating dental restorations must be revised and mechanisms involving porcelain to zirconia bonding must be well understood.

In dental practice, restorations having zirconia frameworks are fabricated using the computer-aided design and computer-aided manufacturing systems, which may be veneered by a tooth-colored porcelain to improve the esthetics. However, chipping and debonding of the feldspathic porcelain veneer have been one of the most common
Correspondence: Hossein Bagheri Department of Operative Dentistry, Faculty of Dentistry, Dental Materials Research Center, Mashhad University of Medical Sciences, Ferdowsi Campus, Vakilabad Highway, 9177948959

Mashhad, Iran

Tel +989153132180

Fax +985138829500

Email bagherih@mums.ac.ir 
concerns in porcelain fused to zirconia restorations. ${ }^{2}$ Several strategies have been developed to improve bonding between zirconia and porcelain. Despite several investigations, ${ }^{3-10}$ the bonding mechanism between zirconia and veneering ceramic remains ununderstood. The routine approach usually relies on the roughening of zirconia surface, using sandblasting technique. However, other methods such as conventional silica coating, ${ }^{7}$ linear application, ${ }^{11}$ and laser surface treatment ${ }^{12,13}$ have been introduced for porcelain to zirconia bonding.

Modification of zirconia surface using silica glasses was introduced for improving the zirconia-to-resin bonding strength. ${ }^{14,15}$ Moreover, this method would make it possible to improve the bonding between zirconia and veneering porcelain, since the feldspathic porcelain may fuse to the silica layer during firing. However, conventional methods for silica coating have been criticized for their adverse effects on mechanical properties (ie, producing surface flaws and phase transformations), as well as their expense. ${ }^{14}$ Therefore, other methods, such as sol-gel process, have been used for silica coating of zirconia ceramics. ${ }^{14,16}$

A sol-gel method provides the powderless processing of glasses and thin films directly from the solution. During this process, an oxide network forms through hydrolysis and condensation of metal alkoxide precursors. Recently, sol-gel process has been used for silica coating of zirconia to improve the resin-zirconia bonding. ${ }^{14}$ This procedure is more conservative, less expensive, and requires less space compared to conventional sandblasting and tribochemical processes. ${ }^{14}$ Sol-gel dip coating, described well in 1991 by Brinker et al, ${ }^{17}$ consists of the withdrawal of a substrate from a sol by gravitational draining, solvent evaporation, and finally performing further condensation reactions, which makes a solid thin film. Compared to other thin film forming techniques, this method is more convenient. ${ }^{17}$ In this study, we have used this technique for surface modification of dental zirconia, through formation of a silica or aluminosilicate coating, in order to improve the bonding of porcelain to zirconia. The formation and characterization of the created coating was studied using Fourier transform infrared spectroscopy (FT-IR), X-ray diffraction (XRD), scanning electron microscopy (SEM), and energy-dispersive X-ray analysis (EDS). Microtensile bond strength ( $\mu$ TBS) test was used to quantify the bond between the Y-TZP and the veneering porcelain. In $\mu$ TBS approach, test specimens are prepared as small beams, having a cross-sectional area of $1 \times 1 \mathrm{~mm}^{2}$, while the bonded interface is placed at the middle (Figure 1). The smaller cross-sectional area may decrease the defect concentration in the interface, which in turn lowers the probability of the presence of a defect with a critical size in a crack-opening orientation relative to the applied load. ${ }^{18}$

The aim of this in vitro study was to evaluate the effect of silica and aluminosilicate nanocomposite coating of zirconiabased dental ceramic by sol-gel dip-coating technique on the bond strength of veneering porcelain to Y-TZP.

\section{Materials and methods}

Frothy Y-TZP blocks $\left(10 \times 10 \times 3 \mathrm{~mm}^{3}\right)$ were prepared (DD Bio ZW iso Zirkonoxid; Dental Direkt GmbH, Spenge, Germany) and sintered as instructed by the manufacturer. The blocks were assigned to four experimental groups ( $n=10 /$ group): C, without any further surface treatment as the control group; S, sandblasted using $110 \mu \mathrm{m}$ alumina

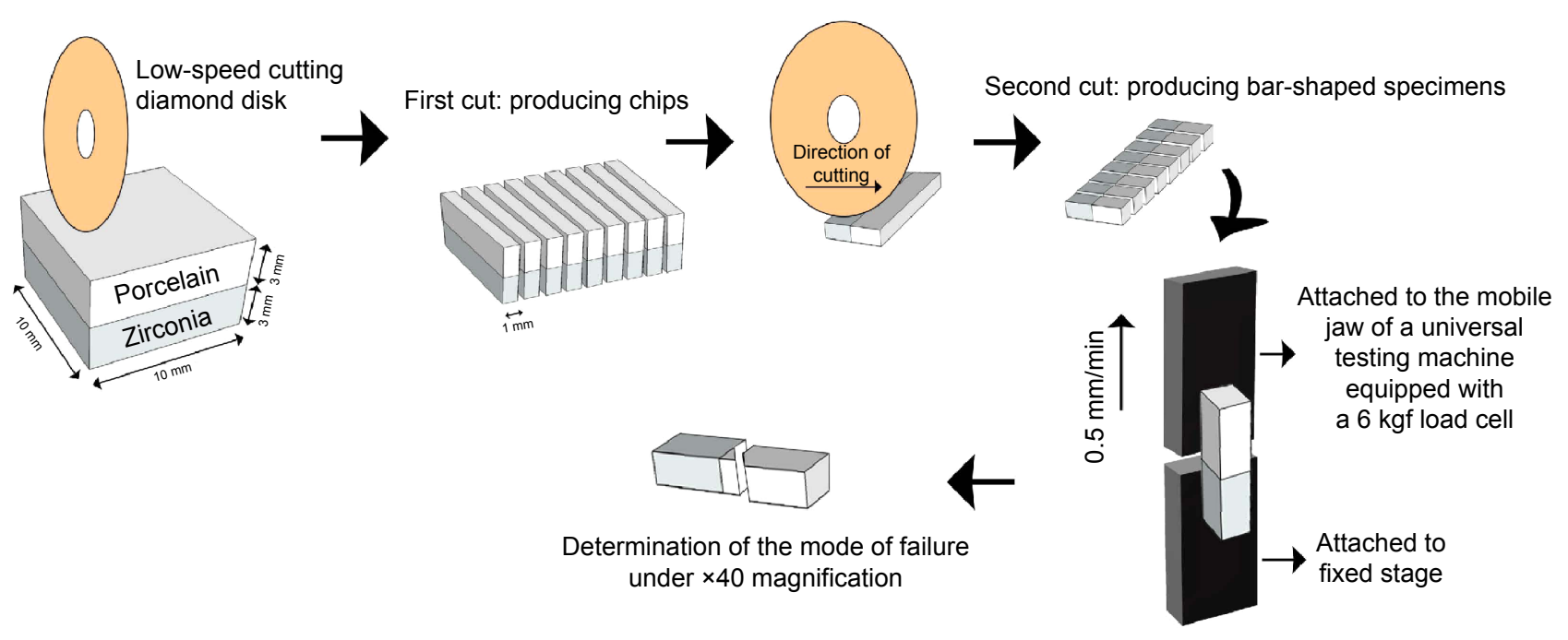

Figure I Schematic explanation of sample preparation for microtensile bond strength experiment. 
powder under 2.5 bar and the tip distance of $10 \mathrm{~mm}$; Si, silica sol dip coating + calcination; $\mathrm{Si} / \mathrm{Al}$, aluminosilicate sol dip coating + calcination.

\section{Sol preparation}

Silica sol was prepared as described previously. ${ }^{19}$ Briefly, tetraethyl orthosilicate (TEOS) was added to a solution containing nitric acid $\left(\mathrm{HNO}_{3}\right)(\geq 65 \%$, Sigma-Aldrich Co., St Louis, MO, USA) and ethanol (EtOH) 99.8\% (Merck \& Co., Inc., Whitehouse Station, NJ, USA) under stirring. After 10 minutes, deionized distilled water (DDW) was added to the solution and the obtained sol was left under stirring for 1 hour in the ambient temperature. The molar ratio of reagents was TEOS: $\mathrm{HNO}_{3}:$ EtOH: $\mathrm{H}_{2} \mathrm{O}=1: 1.7: 6: 2$.

Aluminosilicate sol was prepared as previously mentioned by Cao et al. ${ }^{20}$ Partially hydrolyzed silica sol was first prepared by dissolving TEOS $(67 \mathrm{~mL})$ in $100 \mathrm{~mL}$ isopropanol and a solution containing water and $\mathrm{HNO}_{3}$ was added with stirring at room temperature. The stirring was continued for 1 hour; thereafter, $7.36 \mathrm{~g} \mathrm{Al}\left(\mathrm{NO}_{3}\right)_{3} \cdot 9 \mathrm{H}_{2} \mathrm{O}$ dissolved in $50 \mathrm{~mL}$ DDW was added to this sol, with vigorous stirring.

\section{Coating of Y-TZP blocks}

To provide a clean surface before coating, the blocks were vigorously washed under running distilled water, placed in an acetone/ethanol ultrasonic bath for 20 minutes, and then air-dried. The Y-TZP blocks were coated either by the silica or aluminosilicate sol using a dip-coating device $(80 \mathrm{~mm} / \mathrm{s}$, dipping time: 60 seconds $)$ and calcinated at $400^{\circ} \mathrm{C}\left(5^{\circ} \mathrm{C} / \mathrm{min}\right)$ for 2 hours.

\section{Porcelain veneering}

A thermally compatible veneering porcelain (DD Nature $\mathrm{Zr}$; Dental Direkt $\mathrm{GmbH}$ ) with matching coefficient of thermal expansion (CTE) was fired on the coated Y-TZP surface under the instructed conditions in a dental porcelain firing furnace (EP3000; Ivoclar-Vivadent, Lichtenstein, Germany). The coated Y-TZP blocks were washed under running distilled water to remove any possible remnants from the coating procedure. A layer of thin porcelain dough (porcelain wash), prepared by mixing the porcelain powder and the supplied liquid, was painted on the Y-TZP surface using a fine brush and fired. In the next step, a polymethyl methacrylate split mold was used to condense a $3 \mathrm{~mm}$ thick layer of the porcelain (main body), while the excess water was removed using an absorbent tissue. Finally, the split mold was removed gently, and the porcelain body was fired in recommended condition as presented in Table 1.

\section{Characterization of coatings}

FT-IR, XRD, SEM, and EDS were used to characterize the coating and the nature of the bonding between the coating and zirconia. To examine the zirconia-porcelain bond strength, a microtensile approach was chosen.

The FT-IR transmittance spectra of the calcinated prepared gel were obtained in the spectral area of $4,000-400 \mathrm{~cm}^{-1}$, using a Bruker FT-IR extended spectrometer (Bruker Optics Inc., Billerica, MA, USA), with a resolution of $4 \mathrm{~cm}^{-1}$.

SEM imaging $(20 \mathrm{kV})$ and EDS were conducted using a SEM unit (S360; Oxford Co., Cambridge, UK) equipped with an energy-dispersive spectroscopy detector (INCA Energy 300; Oxford Instruments, Oxford, UK), after gold sputtering (Polaron E5200; Watford, Hertfordshire, UK). The phase present in the coatings was analyzed using X'Pert PRO PW 3040/60 XRD (Phillips, Almelo, the Netherlands) with a $\mathrm{Cu}-\mathrm{K} \alpha$ monochromatic radiation $(\lambda=1.54178 \AA)$ source.

\section{Microtensile bond strength test}

To evaluate the efficacy of the bond between Y-TZP and overlayered porcelain, porcelain-bonded blocks were embedded in transparent polymethyl methacrylate resin and sectioned using a low-speed computerized numerical control cutting machine (Nemo, Mashhad, Iran) under water cooling to fabricate bar-shaped specimens with a $1 \mathrm{~mm} \times 1 \mathrm{~mm}$ zirconiaporcelain bond area (Figure 1). The bars were screened under a stereomicroscope using $\times 40$ magnification (Zoom; Blue Light Industry USA Inc., La Habra, CA, USA) for any probable cracks or chipped edges, and 12 sound bar specimens were selected randomly for each group. To simulate the thermal conditions of oral cavity, the bar specimens were subjected to a thermocycling regime $\left(2,000\right.$ cycles, $5^{\circ} \mathrm{C}-55^{\circ} \mathrm{C}$, dwell time: 20 seconds). After thermocycling, the specimens were mounted on a split holder using cyanoacrylate glue and subjected to $\mu$ TBS testing using a universal testing machine

Table I Firing conditions of veneering porcelain as instructed by the manufacturer

\begin{tabular}{lllllll}
\hline Firing step & $\begin{array}{l}\text { Start } \\
\text { temperature }\left({ }^{\circ} \mathbf{C}\right)\end{array}$ & $\begin{array}{l}\text { Dry time } \\
\text { (minutes) }\end{array}$ & $\begin{array}{l}\text { Heat rate } \\
\left({ }^{\circ} \mathbf{C} / \text { min) }\right.\end{array}$ & $\begin{array}{l}\text { Final } \\
\text { temperature }\left({ }^{\circ} \mathbf{C}\right)\end{array}$ & $\begin{array}{l}\text { Holding time } \\
(\mathbf{m i n u t e s})\end{array}$ & $\begin{array}{l}\text { Vacuum } \\
(\mathbf{m i n u t e s})\end{array}$ \\
\hline Wash firing & 440 & 2 & 45 & 860 & 1.5 & 3 \\
Main body firing & 440 & 4 & 45 & 830 & 1.5 & $3 \mathrm{Yes}$ \\
\hline
\end{tabular}


(STM20; Santam, Tehran, Iran) equipped with a 6 kgf load cell under the load rate of $0.5 \mathrm{~mm} / \mathrm{min}$ (Figure 1).

\section{Statistical analysis}

The effect of different surface treatments on the zirconiaporcelain $\mu$ TBS was examined using one-way analysis of variance (ANOVA) procedure, which was followed by Tukey's post hoc pairwise comparison $(\alpha=0.05)$ using SPSS V11.5 software.

\section{Results}

\section{Fourier transform infrared spectroscopy}

Figure 2 shows the FT-IR spectra of calcined silica and aluminosilicate. Silica spectrum shows the IR band near $800 \mathrm{~cm}^{-1}$, which can be assigned to $\mathrm{Si}-\mathrm{O}-\mathrm{Si}$ symmetric stretching vibrations and a peak at $464 \mathrm{~cm}^{-1}$, which is due to $\mathrm{O}-\mathrm{Si}-\mathrm{O}$ bending vibrations. ${ }^{21}$ The strong and broad band at $1,082 \mathrm{~cm}^{-1}$ with a shoulder at $\sim 1,200 \mathrm{~cm}^{-1}$ is in the region that is usually assigned to the transverse and longitudinal optical modes of the $\mathrm{Si}-\mathrm{O}-\mathrm{Si}$ asymmetric stretching vibrations. ${ }^{22}$ Moreover, the position and shape of the main $\mathrm{Si}-\mathrm{O}$ vibrational band at $1,082 \mathrm{~cm}^{-1}$ show a stoichiometric silicon dioxide structure. ${ }^{23}$
The wide IR band in the range of $3,000-3,800 \mathrm{~cm}^{-1}$ is due to the stretching vibration of $\mathrm{H}_{2} \mathrm{O}$ molecules, and the band at $1,644 \mathrm{~cm}^{-1}$ is related to the corresponding bending. ${ }^{21}$

FT-IR spectrum obtained from aluminosilicate composite indicated that the peak at $1,082 \mathrm{~cm}^{-1}$ was shifted to $1,073 \mathrm{~cm}^{-1}$, due to the incorporation of aluminum ions, confirming the formation of Al-O-Si bonds. In the presence of $\mathrm{Al}^{3+}$ ions as the second neighbor of the $\mathrm{Si}-\mathrm{O}$, the $\mathrm{Al}^{3+}$ ions will attract the oxygen molecule stronger than Si. Hence, the $\mathrm{Si}-\mathrm{O}-\mathrm{Al}$ asymmetric stretching would be located at a lower wavenumber than $\mathrm{Si}-\mathrm{O}-\mathrm{Si}$ stretching. ${ }^{2}$

\section{X-ray diffraction}

Figure 3 shows the XRD pattern of silica and aluminosilicatecoated Y-TZP samples after calcination. Analysis of the diffraction pattern of silica-coated sample showed the presence of silicon dioxide and tetragonal structure of zirconium silicate $\left(\mathrm{ZrSiO}_{4}\right)$. XRD pattern of aluminosilicate sample showed the formation of aluminum silicates $\left(\mathrm{Al}_{2} \mathrm{SiO}_{5}\right)$, predominantly as sillimanite, kyanite, and tetragonal $\mathrm{ZrSiO}_{4}$. Moreover, hexagonal zirconium aluminum oxide with the chemical formula of $\mathrm{Zr}_{5} \mathrm{Al}_{3} \mathrm{O}_{0.5}$ was also detected. Overall, the

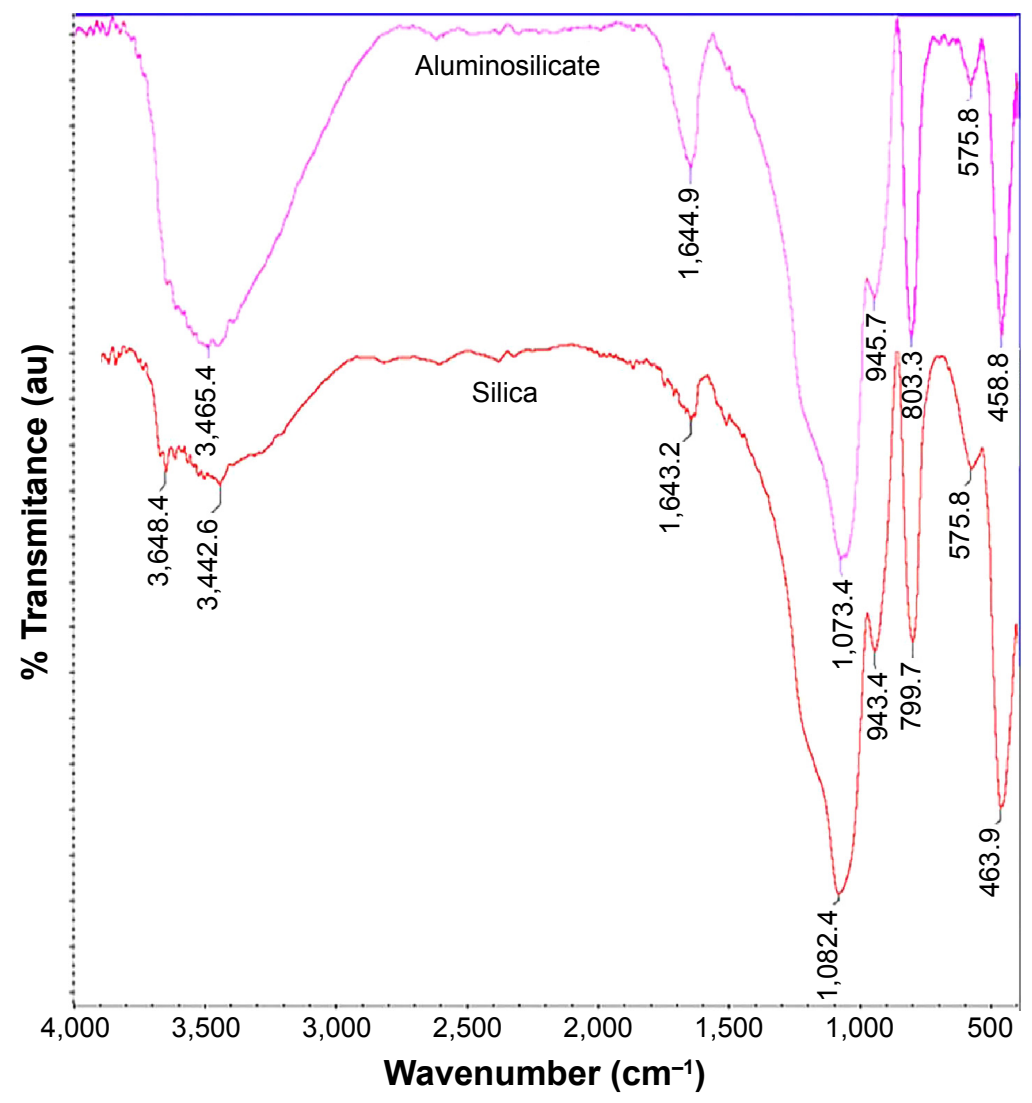

Figure 2 FT-IR spectra of silica (red line) and aluminosilicate (purple line) coating materials. Abbreviation: FT-IR, Fourier transform infrared spectroscopy. 

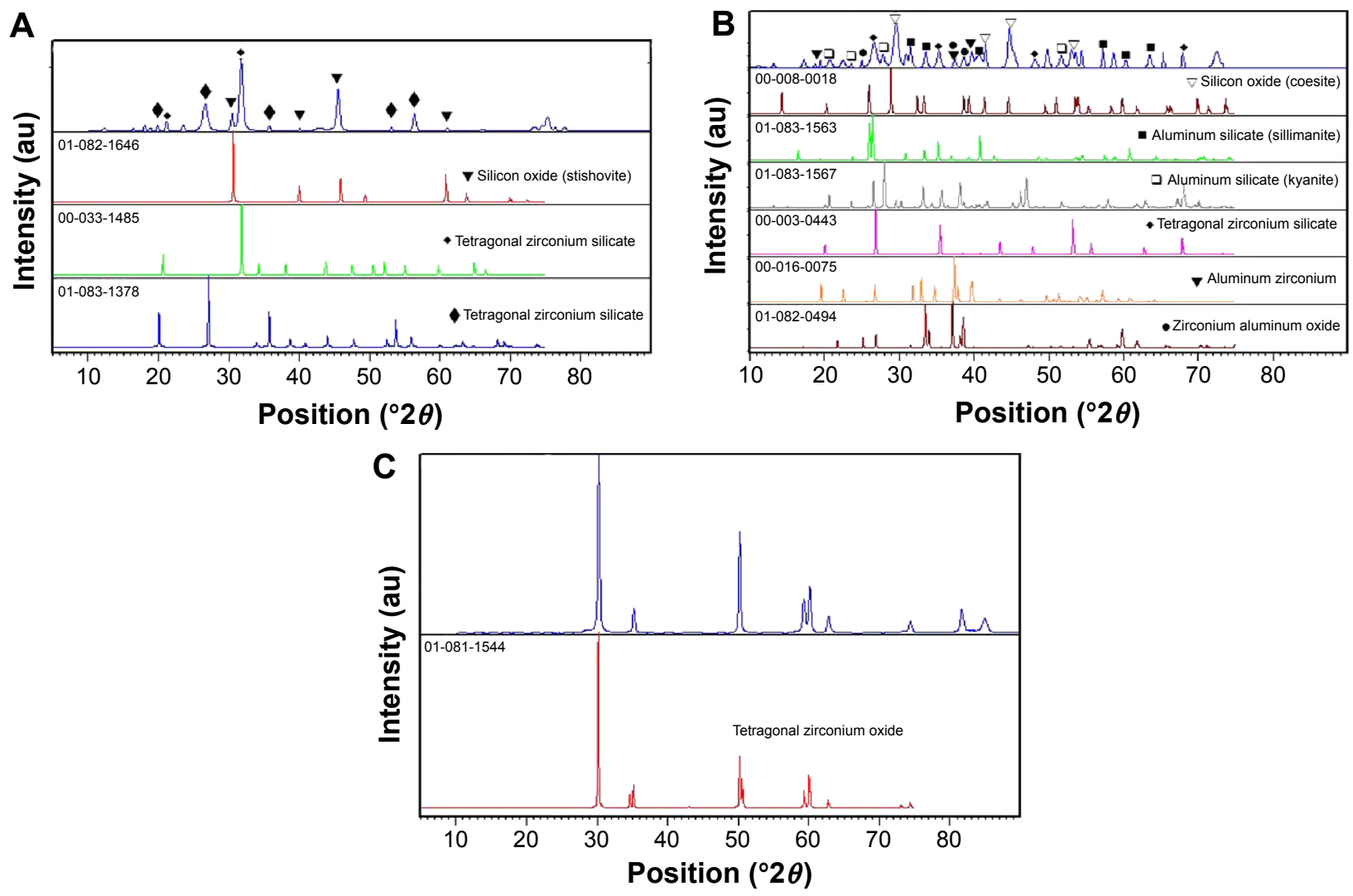

Figure $3 \mathrm{XRD}$ analysis of silica and silica/alumina samples.

Notes: (A) Silica-coated, (B) aluminosilicate-coated, and (C) uncoated zirconia. The first pattern in each figure was obtained from the sample. Abbreviation: $\mathrm{XRD}, \mathrm{X}$-ray diffraction.

diffraction pattern of coated samples showed the formation of new phases, which implies a chemical bond between the Y-TZP substrate and the overlaying coatings.

\section{Scanning electron microscopy and energy-dispersive $\mathrm{X}$-ray analysis}

Figures 4A to D show the SEM images obtained from the surface of specimens after different surface treatments. SEM examination showed the formation of a uniform silica or aluminosilicate layer on the Y-TZP surface (Figure 4C and D). The cross-sectional SEM examination (figures $5 \mathrm{~A}$ to $\mathrm{D}$ ) indicated that interfacial silica or aluminosilicate layers were $\sim 10$ $\mu \mathrm{m}$ thick (Figure 5C and D).

EDS pattern demonstrated the presence of silicon and oxygen (silica) on the silica-coated samples and a combination of silicon, aluminum, and oxygen on the aluminosilicatecoated surfaces (Figure 4).

\section{Microtensile bond strength}

The mean values for $\mu \mathrm{TBS}$ were in order of $\mathrm{Si} / \mathrm{Al}>\mathrm{Si}>\mathrm{C}>\mathrm{S}$ among the groups in this study. Minimum bonding strength was observed in the sandblasted group $(16.74 \pm 2.00 \mathrm{MPa})$, which was significantly lower than in the other groups (Figure 6). The maximum $\mu$ TBS mean value was obtained in the $\mathrm{Al} / \mathrm{Si}$ group (24.08 $\pm 3.44 \mathrm{MPa})$, followed by the Si group $(22.82 \pm 2.44 \mathrm{MPa})$, having no statistically significant difference $(P=0.67)$. The descriptive and analytic statistical data for $\mu$ TBS are presented in detail in Figure 6. All specimens were fractured in a mixed fashion including the interfacial area and the porcelain part.

\section{Discussion}

In this study, we have used a sol-gel dip-coating approach to improve the bonding between the dental (Y-TZP) and the veneering porcelain. Sol-gel approach for Y-TZP coating is a noninvasive method for surface modification to improve the Y-TZP bonding to silicate-based veneering ceramics. Tribochemical methods also can be used for surface modification of zirconia; however, similar to sandblasting in the present study, they may have adverse effect on the bond strength through phase transformation, induced by the collision of silica-coated alumina particles. Sol-gel technique requires less expensive equipment and chemical reagents, compared to the sandblasting unit and silica-coated alumina sand particles. 

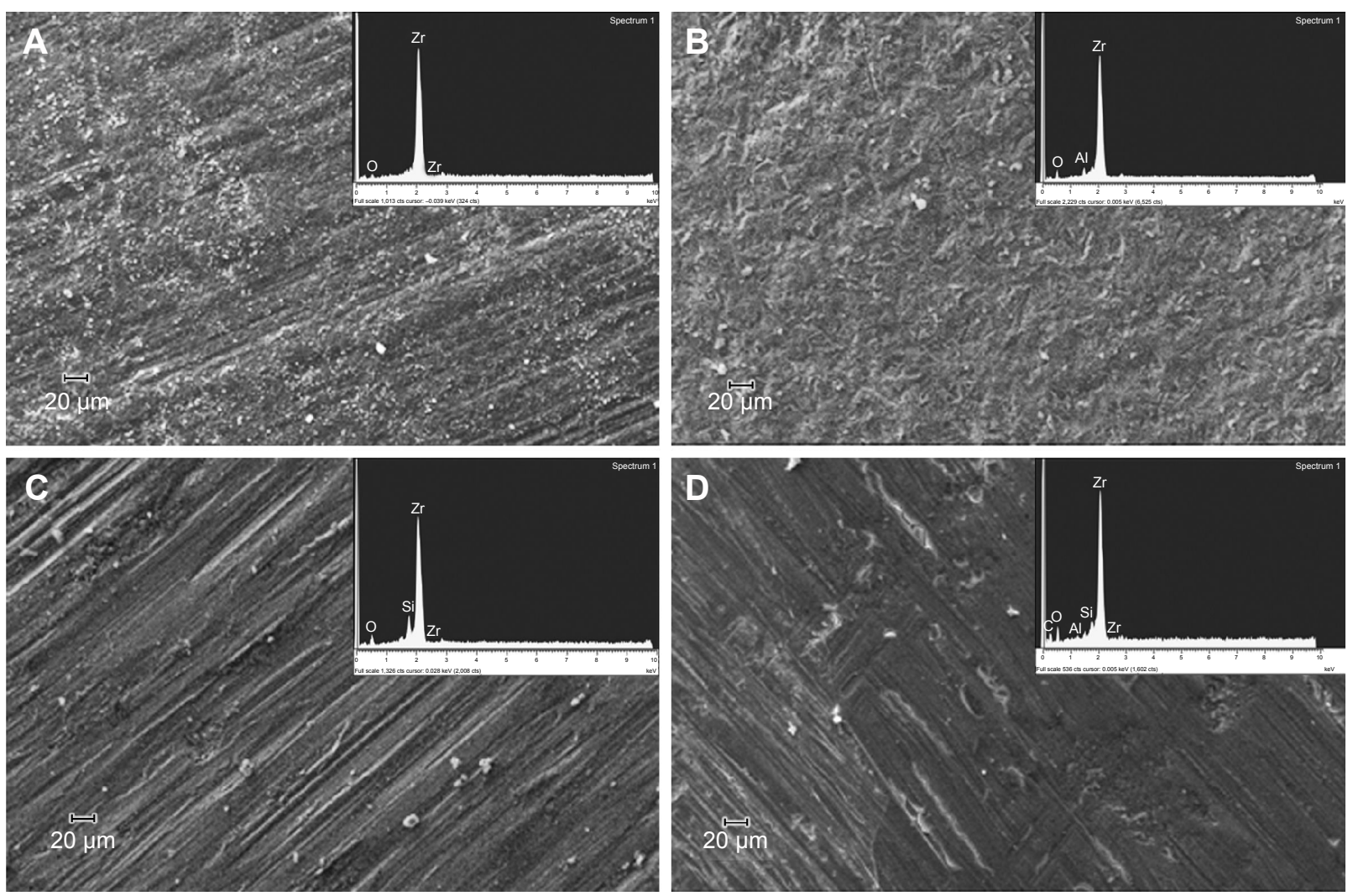

Figure 4 SEM and EDS (insert) examination of different surface treatments/coatings.

Notes: (A) No treatment (C), (B) sandblasted zirconia surface (S), (C) silica coating (Si), and (D) aluminosilicate coating (Si/Al). Magnification $\times 600$.

Abbreviations: SEM, scanning electron microscopy; EDS, energy-dispersive X-ray analysis.
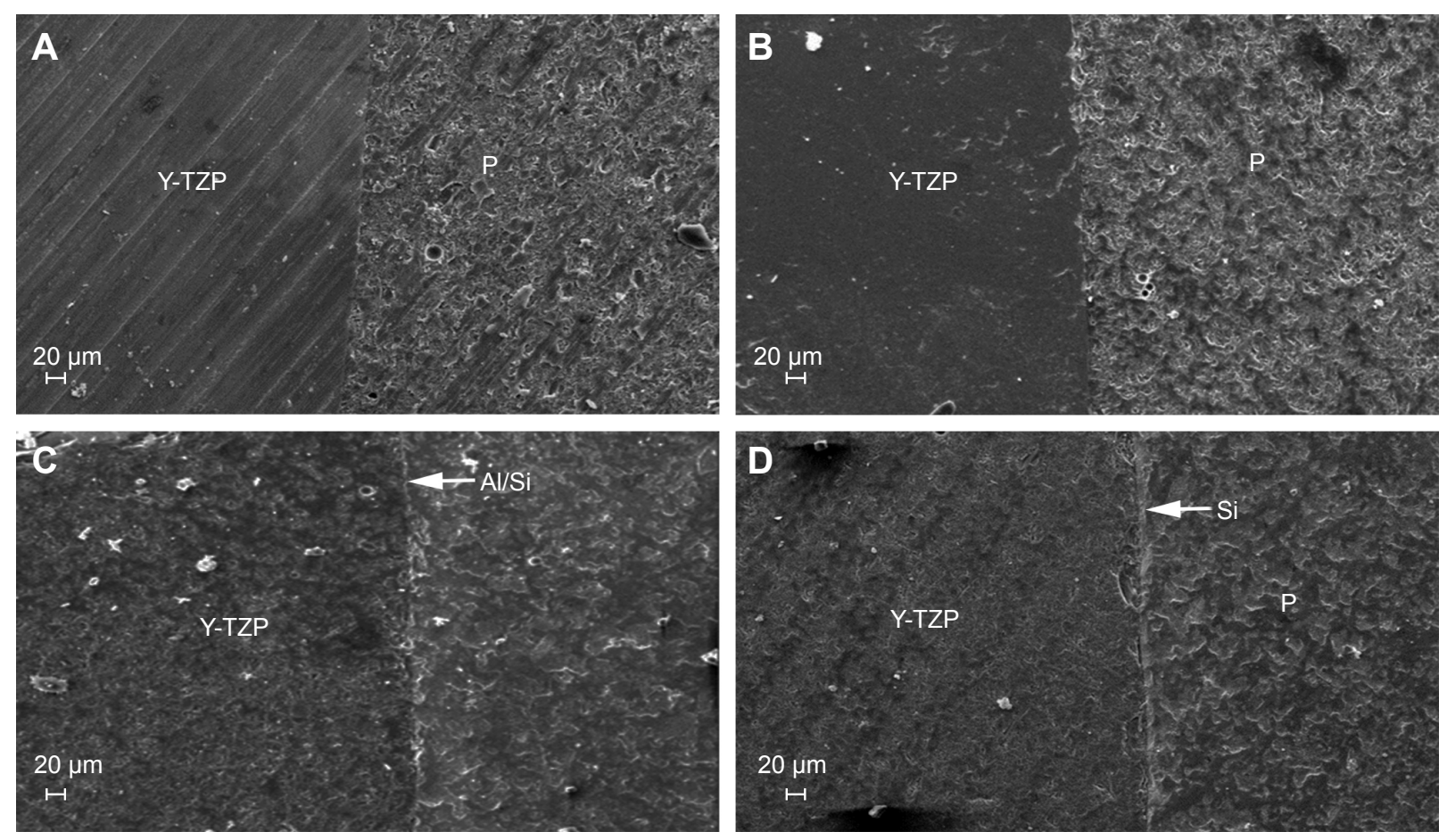

Figure 5 Cross-sectional SEM imaging of porcelain bonded to zirconia.

Notes: (A) Control group, (B) sandblasted zirconia, (C) Al/Si sol-coated, and (D) Si sol-coated. White arrows indicate the cross-sectional view of aluminosilicate (Al/Si) and silica (Si) coatings. Magnification $\times 600$.

Abbreviations: SEM, scanning electron microscopy; Y-TZP, yttria-stabilized tetragonal zirconia polycrystal; P, porcelain; Si, silica coating; Al/Si, aluminosilicate coating. 


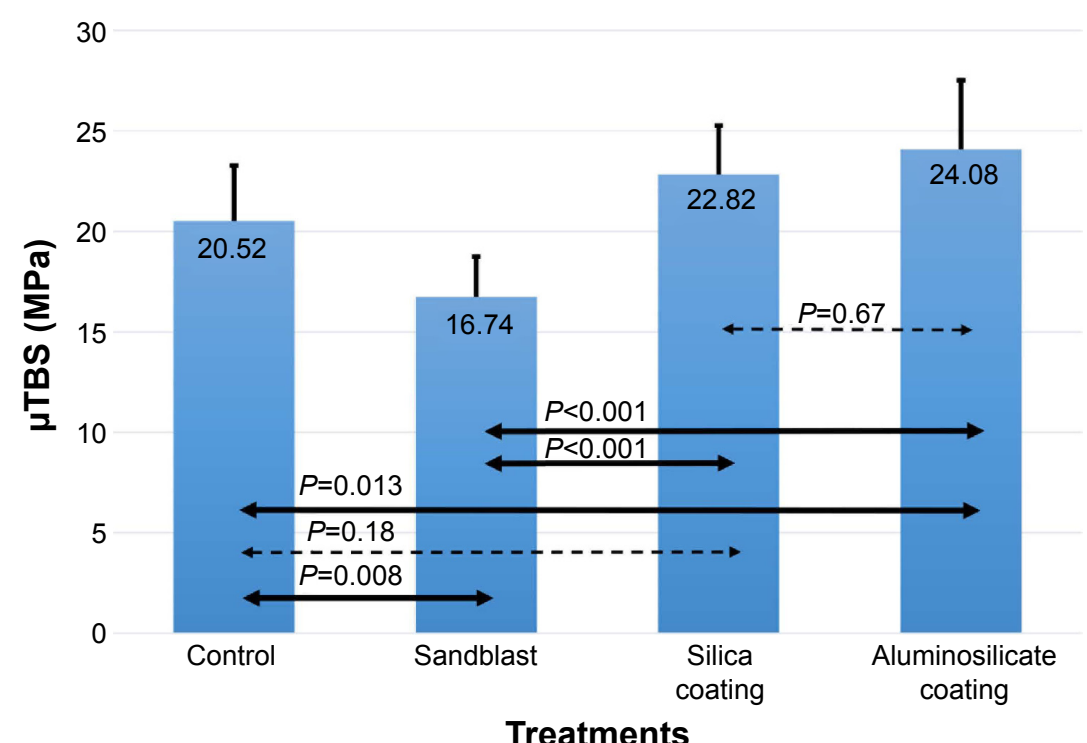

Figure 6 Mean values and standard deviation for $\mu$ TBS experiment.

Note: Arrows indicate the Tukey's analysis results. Solid arrows indicate statistically significant difference, dotted arrows indicate no statistically significant difference. Abbreviation: $\mu \mathrm{TBS}$, microtensile bond strength.

A recent study ${ }^{24}$ has shown that the veneering porcelain would not chemically interact with the Y-TZP during the firing. However, during sol-gel dip-coating process used in this study, a silica or an aluminosilicate network forms in two steps through a sol-gel process, consisting of a hydrolysis and the consequent polycondensation reactions to form a silica or an aluminosilicate network. Both XRD and FT-IR analysis in this study confirmed the formation of silica and aluminosilicate after heat treatment. During the dip-coating process, a silica or an aluminosilicate layer forms on the Y-TZP surface by the interaction of hydroxyl groups of silica or aluminosilicate particles with the hydroxyl groups of Y-TZP on the surface. ${ }^{14}$ This is followed by rapid concentration due to gravitational draining, concomitant with evaporation and condensation reaction. ${ }^{17}$ By heat treatment, the diffusion of metallic ions provokes the formation of new intermediate phases, as indicated in this study.

In the present study, a microtensile design was chosen to evaluate the bond strength between porcelain and zirconia. Fischer and Stawarczyk ${ }^{25}$ have concluded that shear bond strength design cannot evaluate the interfacial bond strength between Y-TZP and porcelain, since the shear force may develop tensile stresses in porcelain adjacent to the interface, which will result in cohesive fracture in the porcelain substrate.

This study showed that sandblasting might significantly weaken the porcelain-Y-TZP interface. There is a general agreement among studies that sandblasting of Y-TZP has negative effect on the bond strength of veneering porcelain. . $24,26,27$ This destructive effect has been related to the tetragonal to monoclinic solid phase transformation, induced by the collision of alumina particles during sandblasting. ${ }^{10,24,26,27}$ Significantly lower CTE in monoclinic form may induce tensile (rather than compressive) stresses at the surface layer, which causes failure in lower shear stresses. ${ }^{25}$ Wang et al also have mentioned that the toughness of zirconia/veneer interface without any treatment is significantly higher than that of interfaces subjected to airborne-particle abrasion. ${ }^{9}$ Using fracture mechanics, they have suggested another reason for the diminishing effect of sandblasting. Their study showed that sandblasting using $110 \mu \mathrm{m}$ alumina particles may act as a critical factor in developing flaws in the surface, decreasing the interfacial fracture toughness. ${ }^{9}$ Other previous studies also have shown the weaken interface between Y-TZP and layering ceramics after sandblasting surface treatment. ${ }^{24,28-30}$ So, it can be said that although sandblasting increases the surface roughness and bond area, the effect of resulted mechanical retention may not outweigh the influence of the mechanical and thermal residual stresses. ${ }^{8}$

Maximum bond strength values were obtained in aluminosilicate-coated followed by silica-coated samples. The difference between these two groups was not statistically significant; however, in comparison with sandblasted and control groups, the mean values in $\mathrm{Al} / \mathrm{Si}$ group were significantly increased. The evidence of formation of $\mathrm{ZrSiO}_{4}$ and zirconium aluminum oxide and intermetallic compounds (ie, a chemical bond) in the present study can 
explain the relative higher bond strength in silica- and aluminosilicate-coated samples. Furthermore, the cell volume of $\mathrm{ZrSiO}_{4}$ is four times larger than that of zirconia; hence, a compressive stress would be created in the coating, which can enhance the bonding. In addition, it is possible that after porcelain firing, such new phases appear as the consequence of silica content of the veneering porcelain in the control group. This can be evident in the relatively equal bond strength of silica-coated and control specimens. However, as the bond strength in aluminosilicate-coated samples was significantly increased, it can be postulated that the formation of new phases such as $\mathrm{Al}_{2} \mathrm{SiO}_{5}$ and zirconium aluminum oxide may improve the thermal and mechanical compatibility (elastic modulus [EM] and CTE of two adherents) at the interface, which must be studied in more detail in future studies.

The mode of failure must be considered when discussing about an interfacial bond strength. In this study, all specimens were fractured in a mixed fashion including the interfacial area and the porcelain part. The failure pattern is related to factors that cause increased stress. These factors are the difference and mismatch of the EM and CTE of porcelain and zirconia, as well as the test methodology. ${ }^{31-33}$ The difference in EM and CTE of porcelain and zirconia is recognized as the determinant factor for inducing residual stresses in the adherent.

Studies about the mechanics of veneered Y-TZP debonding are under progress yet, although Nishigori et $\mathrm{al}^{8}$ reported that the fracture initiates from the veneer ceramic. In this study, the veneering porcelain may integrate to the silica and aluminosilicate coating, due to the sintering of silica content of porcelain and coating, while the newly formed interface between coating and Y-TZP remains the weakest zone of porcelain-Y-TZP junction. Similar failure pattern with different mean bond strength levels between coated and uncoated groups may imply that in the present study, the fracture had initiated in the interfacial zone, but not in the porcelain, which must be studied in more detail in the future.

\section{Conclusion}

Considering the limitations of this in vitro study, the results showed that aluminosilicate sol-gel dip coating can be considered as a convenient, less expensive, reliable method for improving the bond strength between Y-TZP ceramics and the veneering porcelain. Further studies are needed to evaluate the effect of different variables such as the calcination and dipcoating processes on the quality of porcelain-Y-TZP bond.
In addition, the fracture mechanics of bond failure must be studied in more detail.

\section{Acknowledgment}

This manuscript is a part of thesis for postgraduate degree in prosthodontics. The research was funded by the Vice Chancellor for Research and Technology, Mashhad University of Medical Sciences, Mashhad, Iran.

\section{Disclosure}

The authors report no conflicts of interest in this work.

\section{References}

1. Garvie R. Stabilization of the tetragonal structure in zirconia microcrystals. J Phys Chem. 1978;82(2):218-224.

2. Roediger M, Gersdorff N, Huels A, Rinke S. Prospective evaluation of zirconia posterior fixed partial dentures: four-year clinical results. Int J Prosthodont. 2010;23(2):141-148.

3. Fischer J, Grohmann P, Stawarczyk B. Effect of zirconia surface treatments on the shear strength of zirconia/veneering ceramic composites. Dent Mater J. 2008;27(3):448-454.

4. Saito A, Komine F, Blatz MB, Matsumura H. A comparison of bond strength of layered veneering porcelains to zirconia and metal. J Prosthet Dent. 2010;104(4):247-257.

5. Fischer J, Stawarczyk B, Sailer I, Hämmerle CH. Shear bond strength between veneering ceramics and ceria-stabilized zirconia/alumina. J Prosthet Dent. 2010;103(5):267-274.

6. Kim H-J, Lim H-P, Park Y-J, Vang M-S. Effect of zirconia surface treatments on the shear bond strength of veneering ceramic. J Prosthet Dent. 2011;105(5):315-322.

7. Oguri T, Tamaki Y, Hotta Y, Miyazaki T. Effects of a convenient silica-coating treatment on shear bond strengths of porcelain veneers on zirconia-based ceramics. Dent Mater J. 2012;31(5):788-796.

8. Nishigori A, Yoshida T, Bottino MC, Platt JA. Influence of zirconia surface treatment on veneering porcelain shear bond strength after cyclic loading. J Prosthet Dent. 2014;112(6):1392-1398.

9. Wang G, Zhang S, Bian C, Kong H. Effect of zirconia surface treatment on zirconia/veneer interfacial toughness evaluated by fracture mechanics method. J Dent. 2014;42(7):808-815.

10. Inokoshi M, Yoshihara K, Nagaoka N, et al. Structural and chemical analysis of the zirconia-veneering ceramic interface. J Dent Res. 2015; 95(1):102-109.

11. Aboushelib MN, Kleverlaan CJ, Feilzer AJ. Microtensile bond strength of different components of core veneered all-ceramic restorations: Part II: zirconia veneering ceramics. Dent Mater. 2006;22(9):857-863.

12. Ural Ç, Külünk T, Külünk Ş, Kurt M. The effect of laser treatment on bonding between zirconia ceramic surface and resin cement. Acta Odontol Scand. 2010;68(6):354-359.

13. Tuncel I, Turp I, Usumez A. Bond strength of short-pulsed laserirradiated zirconia to veneer ceramic. J Adhes Sci Technol. 2015;29(12): 1190-1199.

14. Lung CYK, Kukk E, Matinlinna JP. The effect of silica-coating by sol-gel process on resin-zirconia bonding. Dent Mater J. 2013;32(1):165-172.

15. Lung C, Liu D, Tsoi K, Matinlinna J. Adhesion promotion of resin to zirconia by silicon nitride hydrolysis. Dent Mater. 2014;30(Suppl 1):e15.

16. Chen C, Chen G, Xie H, Dai W, Zhang F. Nanosilica coating for bonding improvements to zirconia. Int J Nanomedicine. 2013;8:4053-4062.

17. Brinker C, Frye G, Hurd A, Ashley C. Fundamentals of sol-gel dip coating. Thin Solid Films. 1991;201(1):97-108.

18. Armstrong S, Geraldeli S, Maia R, Raposo LHA, Soares CJ, Yamagawa J. Adhesion to tooth structure: a critical review of "micro" bond strength test methods. Dent Mater. 2010;26(2):e50-e62. 
19. Catauro M, Bollino F, Papale F, Gallicchio M, Pacifico S. Influence of the polymer amount on bioactivity and biocompatibility of $\mathrm{SiO}_{2} /$ PEG hybrid materials synthesized by sol-gel technique. Mater Sci Eng C Mater Biol Appl. 2015;48:548-555.

20. Cao Y, Dai W-L, Deng J-F. The synthesis, characterization and application of $\mathrm{Ag}-\mathrm{SiO}_{2}-\mathrm{Al}_{2} \mathrm{O}_{3}$ sol-gel composites. Mater Lett. 2001;50(1): 12-17.

21. Musić S, Filipović-Vinceković N, Sekovanić L. Precipitation of amorphous $\mathrm{SiO}_{2}$ particles and their properties. Braz J Chem Eng. 2011; 28(1):89-94.

22. Innocenzi P. Infrared spectroscopy of sol-gel derived silica-based films: a spectra-microstructure overview. J Non-Crystalline Solids. 2003; 316(2):309-319.

23. Shokri B, Firouzjah MA, Hosseini S, editors. FTIR analysis of silicon dioxide thin film deposited by metal organic-based PECVD. Proceedings of 19th International Symposium on Plasma Chemistry Society; July 27-31; 2009; Bochum, Germany.

24. Inokoshi M, Yoshihara K, Nagaoka N, et al. Structural and chemical analysis of the zirconia-veneering ceramic interface. J Dent Res. 2016;95(1):102-109.

25. Fischer J, Stawarczyk B. Compatibility of machined Ce-TZP/Al 2 O 3 nanocomposite and a veneering ceramic. Dent Mater. 2007;23(12): 1500-1505.

26. Kim S, Cho H, Lee Y, Choi S, Moon H. Bond strength of Y-TZPzirconia ceramics subjected to various surface roughening methods and layering porcelain. Surf Interface Anal. 2010;42(6-7):576-580.
27. Harding AB, Norling BK, Teixeira EC. The effect of surface treatment of the interfacial surface on fatigue-related microtensile bond strength of milled zirconia to veneering porcelain. J Prosthodont. 2012; 21(5):346-352.

28. Mosharraf R, Rismanchian M, Savabi O, Ashtiani AH. Influence of surface modification techniques on shear bond strength between different zirconia cores and veneering ceramics. J Adv Prosthodont. 2011; 3(4):221-228

29. Harding AB, Norling BK, Teixeira EC. The effect of surface treatment of the interfacial surface on fatigue-related microtensile bond strength of milled zirconia to veneering porcelain. J Prosthodont. 2012; 21(5):346-352.

30. Elsaka SE. Influence of surface treatments on the surface properties of different zirconia cores and adhesion of zirconia-veneering ceramic systems. Dent Mater. 2013;29(10):e239-e251.

31. Thompson G. Influence of relative layer height and testing method on the failure mode and origin in a bilayered dental ceramic composite. Dent Mater. 2000;16(4):235-243.

32. Guazzato M, Proos K, Quach L, Swain MV. Strength, reliability and mode of fracture of bilayered porcelain/zirconia (Y-TZP) dental ceramics. Biomaterials. 2004;25(20):5045-5052.

33. Guazzato M, Proos K, Sara G, Swain MV. Strength, reliability, and mode of fracture of bilayered porcelain/core ceramics. Int J Prosthodont. 2004;17(2):142-149.
International Journal of Nanomedicine

\section{Publish your work in this journal}

The International Journal of Nanomedicine is an international, peerreviewed journal focusing on the application of nanotechnology in diagnostics, therapeutics, and drug delivery systems throughout the biomedical field. This journal is indexed on PubMed Central, MedLine, CAS, SciSearch $®$, Current Contents $\AA /$ Clinical Medicine,

\section{Dovepress}

Journal Citation Reports/Science Edition, EMBase, Scopus and the Elsevier Bibliographic databases. The manuscript management system is completely online and includes a very quick and fair peer-review system, which is all easy to use. Visit http://www.dovepress.com/ testimonials.php to read real quotes from published authors. 